Original Research Paper

\title{
Edukasi Tanggap Bencana Melalui Kegiatan Sosialisasi Guna Mewujudkan Masyarakat Desa Pijot Yang Tangguh
}

\author{
Dipo Ario Kusuma ${ }^{1}$, Siti Maryam Ulfa ${ }^{2}$, Arni Emiza Febrianti ${ }^{3}$, Rosiatul Ismi $^{4}$, Siti Nuriah ${ }^{5}$, Nurul \\ Zainiyah $^{6}$, Rina Nuranjanisa ${ }^{7}$, Soraya Rosanti ${ }^{8}$, Ni Komang Eva Yuniasih', Tiara Hesti Amanda ${ }^{10}$, Mila \\ Andara $^{11}$, Lalu Sumardi ${ }^{12^{*}}$
}

Fakultas Keguruan dan Ilmu Pendidikan, Universitas Mataram, Mataram, Indonesia

https://doi.org/10.29303/jpmpi.v3i2.13102

Sitasi: Ulfa, S. M., Febrianti, A. E., Ismi, R., Nuriah, S., Zainiyah, N., Nuranjanisa, R., Rosanti, S., Yuniasih, N. K. E., Amanda, T. H., Andara, M \& Sumardi, L. (2022). Pemetaan Jalur Evakuasi Dan Titik Kumpul Dalam Upaya Mewujudkan Desa Pijot Yang Tanggap Bencana. Jurnal Pengabdian Magister Pendidikan IPA, 5(1)

\section{Article history}

Received: 11 Januari 2022

Revised: 01 Februari 2022

Accepted: 07 Februari 2022

*Corresponding Author: Lalu Sumardi, Fakultas Keguruan dan Ilmu Pendidikan, Universitas Mataram, Mataram, Indonesia;

Email: 1alu.unram@gmail.com

\begin{abstract}
Desa Pijot secara administratif merupakan salah satu dari 15 desa di Kecamatan Keruak, yang teletak pada radius 3 kilometer sebelah timur Ibu Kota Kecamatan Keruak. Desa Pijot memiliki luas wilayah 715 hektar, tersebar pada 8 kepala dusun, dengan jumlah penduduk di Desa Pijot sebanyak 6113 jiwa. Jumlah penduduk yang banyak dan letak daerah yang berada di pesisir pantai dengan tinggi tempat dari permukaan laut sebesar $500 \mathrm{mdpl}$ dan tingkat curah hujan $491 \mathrm{~mm}$. Kondisi Desa Pijot yang secara geografis, geologis, hidrologis dan demografis yang rawan terhadap bencana dengan frekuensi yang cukup tinggi, serta fakta bahwa kesadaran dan pengetahuan masyarakat yang minim dalam melakukan penanggulangan bencana. Untuk itu pengabdi merasa perlu menanamkan pemahaman dan pembelajaran khusus kepada masyarakat melalui kegiatan sosialisasi tanggap bencana darurat. Tujuan kegiatan ini agar masyarakat memiliki pengetahuan terkait penanggulangan bencana dan selalu siap siaga saat terjadi bencana yang sewaktu-waktu bisa terjadi, sehingga dapat mewujudkan masyarakat Desa Pijot yang tangguh dan tanggap bencana.
\end{abstract}

Keywords: Edukasi tanggap bencana; Sosialisasi; Masyarakat

\section{Pendahuluan}

$\mathrm{I}^{\mathrm{n}}$ ndonesia merupakan negara maritim terbesar di dunia dengan laut terluas sebesar 3,9 juta km, pulau terbanyak (17.508) dan terpanjang kedua di dunia setelah Kanada $(81.000 \mathrm{~km})$. Kondisi ini harus diwaspadai, karena kawasan maritim Indonesia merupakan daerah yang secara tektonik sangat labil. Kawasan ini terkenal sebagai salah satu pinggiran benua yang sangat aktif di muka bumi (Dipastono, 2005).

Kondisi geografis, geologis, hidrologis dan demografis yang rawan terhadap bencana dengan frekuensi yang cukup tinggi, memerlukan penanganan bencana yang yang sistimatis. Dalam Undang-Undang Nomor 24 Tahun 2007 tentang penanggulangan bencana, bahwa yang dimaksud dengan bencana adalah peristiwa atau serangkaian peristiwa yang mengancam dan mengganggu kehidupan dan penghidupan masyarakat yang disebabkan oleh faktor alam maupun faktor non alam, sehingga menyebabkan adanya korban jiwa, terjadinya kerusakan lingkungan, kerugian harta dan benda, serta dampak psikologi seperti trauma yang dialami masyarakat.

Dalam Undang-Undang Nomor 24 Tahun 2007 bencana terbagi menjadi 3 jenis yaitu: 1) bencana alam seperti gempa bumi, tsunami, meletusnya gunung api, badai dan kekeringan; 2) bencana sosial karena ulah manusia seperti konflik, perang, serangan teroris, kegagalan teknologi dan hama penyakit; dan 3) bencana yang disebabkan 
campuran alam dan manusia, seperti banjir, kebakaran hutan dan kekurangan pangan (IDEP, 2007). Berdasarkan undang-undang tersebut, maka suatu peristiwa dianggap sebagai bencana jika menimbulkan kerusakan dan kerugian dalam kehidupan masyarakat.

Wilayah pesisir Lombok termasuk daerah rawan terhadap bencana. Pulau Lombok merupakan salah satu pulau terbesar di Provinsi Nusa Tenggara Barat (NTB) juga memiliki tingkat kerawanan yang tinggi terhadap bencana. Hal ini dikarenakan bagian selatan pulau Lombok berhadapan langsung dengan Samudra Hindia yang merupakan pertemuan dua lempeng yaitu lempeng Benua Asia dan lempeng Benua Australia (Santoro, 2019). Salah satu daerah di pulau Lombok yaitu Desa Pijot.

Desa Pijot secara administratif merupakan Desa Induk dan telah melakukan pemekaran menjadi dua Desa yaitu Pijot Induk dan Pijot Utara, serta merupakan salah satu dari 15 desa di Kecamatan Keruak yang teletak pada radius 3 kilometer sebelah timur Ibu Kota Kecamatan Keruak. Desa Pijot memiliki luas wilayah 715 hektar, tersebar pada 8 kepala dusun, yaitu Dusun Pijot Selatan, Dusun Permai Indah, Dusun Pemban Pijot, Dusun Pemban Aji, Dusun Larangan, Dusun Bendera Baru, Dusun Padak Selatan dan Dusun Padak Timur. Sebelah utara Desa Pijot berbatasan langsung dengan Desa Menceh, sebelah timur berbatasan dengan Desa Tanjung Luar dan Ketapang Raya, sebelah selatan berbatasan dengan Desa Ketangge Jaraeng, dan sebelah barat berbatasan dengan desa Pijot Utara dan Menceh (RPJMdes, 2021).

Jumlah penduduk di Desa Pijot sebanyak 6113 jiwa. Jumlah penduduk yang banyak dan letak daerah yang berada di pesisir pantai dengan tinggi tempat dari permukaan laut sebesar $500 \mathrm{mdpl}$ dan tingkat curah hujan $491 \mathrm{~mm}$ (RPJMDes, 2021), membuat daerah ini juga seringkali terdampak bencana. Desa Pijot sering menghadapi permasalahan lingkungan yang serius, seperti sering terjadinya banjir rob yang melanda pemukiman warga, abrasi, dan penyusutan air asin ke arah daratan, gempa bumi serta memungkinkan potensi tsunami terjadi. Daerah yang rawan bencana dengan fakta kesadaran dan pengetahuan masyarakat yang minim tentang penanggulangan kejadian luar biasa/bencana. Untuk itu kita perlu menanamkan pemahaman dan pembelajaran khusus kepada masyarakat agar masyarakat memiliki pengetahuan terkait penanggulangan bencana dan selalu siap siaga saat terjadi bencana yang sewaktuwaktu bisa terjadi.

Setiap orang berhak mendapatkan perlindungan sosial dan rasa aman khususnya bagi kelompok masyarakat rentan bencana dan setiap masyarakat berkewajiban menjaga kehidupan sosial masyarakat yang harmonis, memelihara keseimbangan, keserasian, keselarasan dan kelestarian fungsi lingkungan hidup. Sehingga, sebagai bentuk pengabdian masyarakat dan menyiasati keterbatasan pengetahuan masyarakat tentang bencana, maka perlu dilakukan sosialisasi kepada masyarakat untuk mewujudkan desa Pijot tanggap bencana, yang bertujuan untuk menambah khasanah pengetahuan masayarakat di bidang bencana alam.

\section{Metode}

Metode yang digunakan dalam kegiatan pengabdian ini terdiri dari tiga tahapan, yaitu; observasi, kegiatan sosialisasi, dan kegiatan evaluasi pasca sosialisasi. Kegiatan observasi lapangan dilakukan pada hari Senin, 29 September 2021. Kegiatan ini dilakukan dengan wawancara penduduk setempat dan mengamati beberapa tempat di Desa Pijot yang sering terdampak bencana alam, untuk mengetahui pemahaman masyarakat Desa Pijot terkait dengan pengetahuan kesiapsiagaan bencana. Kemudian, melakukan diskusi dengan perangkat desa, terutama kepala desa terkait dengan optimalisasi penanggulangan bencana yang ada di Desa Pijot, berdiskusi terkait dengan potensi desa, lokasi pengabdian, dan waktu pelaksanaan kegiatan.

Kegiatan sosialisasi dilaksanakan pada hari Rabu, 8 Desember 2021 di Aula Kantor Desa Pijot. Kegiatan ini dihadiri oleh perangkat Desa Pijot, tokoh agama, tokoh masyarakat, serta masyarakat Desa Pijot pada umumnya. Narasumber dalam kegiatan sosialisasi ini adalah Bapak H. Mahyudin, S. Ap. kepala bidang kesiapsiagaan dan pencegahan bencana, Badan Penanggulangan Bencana Daerah Kabupaten Lombok Timur. Pengabdi menjadi fasilitator dalam kegiatan tersebut. Kegiatan sosialisasi dimulai pada pukul 09.00 WITA sampai pukul 12.00 WITA, dimulai dengan penyampaian materi dari narasumber, lalu diikuti dengan sesi diskusi dan tanya jawab bersama dengan peserta yang hadir dalam sosialisasi. 


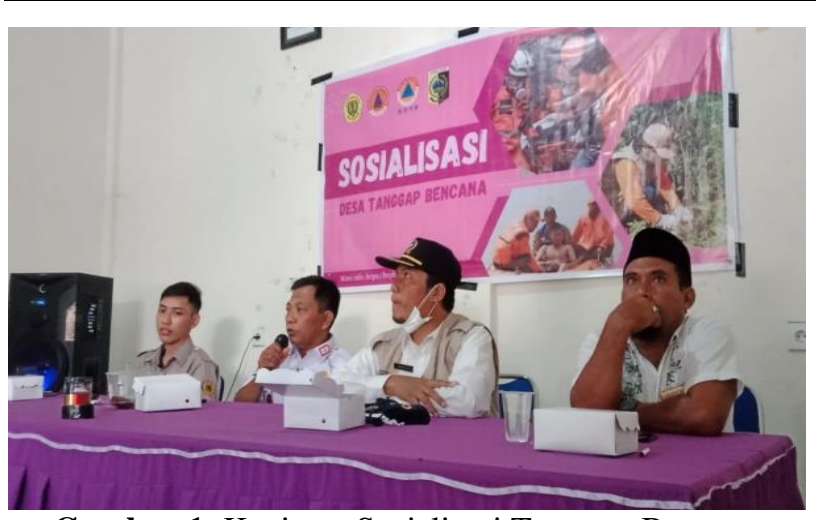

Gambar 1. Kegiatan Sosialisasi Tanggap Bencana di Desa Pijot

Kegiatan selanjutnya yaitu melakukan evaluasi untuk mengetahui tingkat keterlaksanaan dan pencapaian kegiatan sosialisasi yang dilakukan pada masyarakat, yang ditinjau dalam beberapa aspek, diantaranya: 1) tingkat partisipasi aktif masyarakat, dan jumlah peserta yang hadir; 2) ketercapaian tujuan dan materi sosialisai; 3) keaktifan masyarakat dalam diskusi dan tingkat pemahaman masyarakat setelah kegiatan. Kegiatan evaluasi ini dilakukan dengan proses mengamati dan wawancara masyarakat setelah kegiatan berlangsung.

\section{Hasil dan Pembahasan}

Desa Pijot merupakan desa yang berhadap ke laut dan berada sejauh $1 \mathrm{~km}$ dari laut, sehingga bencana alam seperti tsunami sangat mungkin terjadi di desa tersebut. Sebelum melakukan kegiatan sosialisasi, kami terjun langsung ke lapangan untuk mengetahui beberapa tempat yang sering terdampak bencana alam. Kegiatan sosialisasi mengenai tanggap bencana dilaksanakan di Aula kantor Desa Pijot yang dihadiri oleh perwakilan dari masyarakat yang terdiri atas tokoh masyakat, tokoh agama, perangkat desa, dan ketua komunitas perempuan.

Penjabaran tentang hasil sosialisasi ini dapat dijelaskan sebagai berikut:

\section{Pencegahan}

Pencegahan adalah aktivitas atau kegiatan mencegah/menghindari dampak yang sangat buruk yang diakibatkan oleh peristiwa alam yang dapat merugikan masyarakat. Pencegahan ini dapat dilakukan dalam jangka menengah dan jangka panjang. Pencegahan terjadinya bencana salah satunya dapat dilakukan dengan melakukan pelatihan bagi masyarakat atau perwakilan lembaga.

\section{Pelatihan ini dilakukan untuk} mempersiapkan masyarakat Desa Pijot yang tangguh terhadap kejadian luar biasa / bencana. Selain itu, pencegahan dapat dilakukan melalui kegiatan pengelolaan sumber daya yang berkelanjutan, seperti melakukan penanaman pohon mangrove di daerah pinggir pantai, pengelolaan daerah aliran sungai dan daerah pinggir pesisir untuk mencegah terjadinya banjir rob, membuat bendungan dan saluran air sehingga banjir tidak meluap di pemukiman warga (BPBD Lombok Timur, 2021).

\section{Mitigasi Bencana}

Mitigasi bencana merupakan kegiatan yang dilakukan sebelum terjadinya bencana yang dimaksudkan untuk mengantisipasi dan mengurangi adanya korban jiwa dan kerugian materi yang ditimbulkan oleh bencana (Fadli \& Masnun, 2020). Menurut Permana (2021), mitigasi bencana adalah serangkaian upaya yang dilakukan dalam rangka mengurangi resiko bencana, baik melalui pembangunan fisik maupun penyadaran serta peningkatan pemahaman masyarakat terhadap ancaman bencana. Salah satunya yang perlu dilakukan adalah membuat kajian tentang kemungkinan risiko bencana dan memberikan pelatihan terhadap masyarakat yang berada di daerah rawan bencana.

Menurut Djauhari (2014) program mitigasi bencana mengacu pada 2 tahap perencanaan yaitu: 1) perencanaan sebelum kejadian untuk manajemen bencana, mencakup aktivitas-aktivitas mitigasi dan perencanaan bencana; 2) perencanaan serta tindakan sesudah kejadian, meliputi peningkatan standar teknis dan bantuan medis serta bantuan keuangan bagi korban.

Dalam mitigasi bencana perlu dilakukan kegiatan antisipasi untuk meminimalisir dampak resiko dari bencana, seperti membuat peta daerah yang rawan bencana, membuat area titik kumpul dan jalur evakuasi yang bisa dilalui jika terjadi bencana, membagikan leaflet / brosur untuk menambah pengetahuan masyarakat tentang bencana, jalur evakuasi dan kontak yang bisa dihubungi jika terjadi bencana, membentuk tim siaga bencana dan melakukan pelatihan berkala oleh Badan Penanggulangan Bencana, dan banyak hal yang bisa dilakukan terkait mitigasi bencana.

\section{Kesiapsiagaan Masyarakat}


Kesiapsiagaan merupakan kegiatan yang berhubungan dengan antisipasi bencana melalui pengorganisasian yang tepat dan terukur serta berdaya. Di dalam proses pengelolaan bencana, dilakukan presentasi model siklus. Berikut peningkatan kesiapsiagaan yang merupakan bagian dari proses pengelolaan resiko bencana.

Dalam pelaksanaan kegiatan sosialisasi ini, penting diukur ketercapaian hasil pelaksanaan kegiatan dan mengevaluasi faktor pendukung dan penghambat sebagai bahan perbaikan dalam pelaksanaan kegiatan. Berikut uraian singkat dari kegiatan:

\section{Keberhasilan Jumah Target Peserta}

Target Mahasiswa KKN untuk jumlah peserta sosialisasi yang hadir adalah sebanyak 20 orang yang terdiri dari tokoh masyarakat, tokoh agama, tokoh pemuda, dan perangkat desa. Tetapi peserta yang menghadiri kegiatan tersebut melebihi dari target yang ditetapkan. Dengan demikian kegiatan ini dapat dikatakan sangat baik karena jumlah peserta yang hadir melebihi dari target yang ditetapkan. Peserta sosialisasi yang hadir terdiri dari perangkat desa, ketua BPD, kepala dusun, tokoh agama, tokoh masyarakat serta masyarakat pada umumnya.

\section{Tingkat Ketercapaian Kegiatan Sosialisasi}

Kegiatan ini bertujuan untuk meningkatkan pengetahuan serta membangun kesadaran masyarakat yang ada di Desa Pijot dalam meningkatkan kemampuan kesiapsiagaan terhadap bencana dengan mengadakan sosialisasi tanggap bencana. Materi sosialiasi yang disampaikan narasumber antara lain; pengenalan tentang bencana, pencegahan, mitigasi bencana, dan kesipsiagaan terhadap bencana alam. Semua materi tersebut telah dijelaskan oleh pemateri kepada masyarakat dengan bahasa yang baik dan mudah dimengerti.

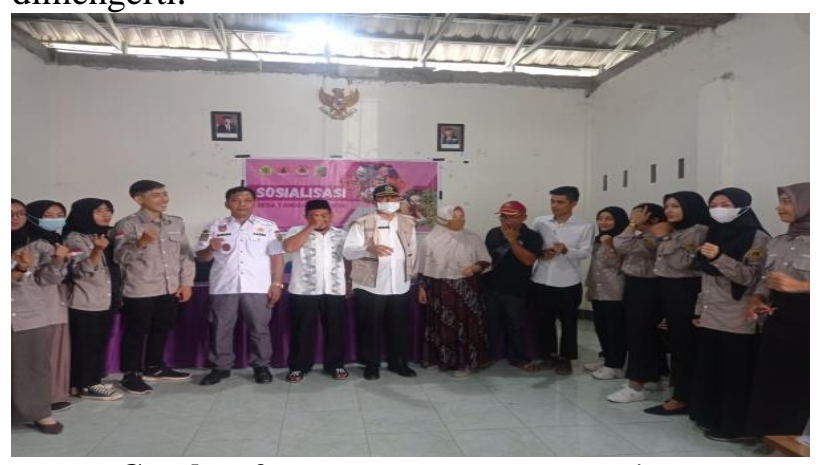

Gambar 2. Foto Bersama Pasca Kegiatan
3. Faktor pendukung dan Penghambat Kegiatan Berdasarkan hasil pembahasan sosialisasi, dapat didentifikasi faktor pendukung dan penghambat dalam pelaksanaan kegiatan sosialisasi sebagai berikut:

1) Faktor pendukung

a. Dukungan dari Kepala Desa Pijot terhadap kegiatan sosialisasi terhadap masyarakat.

b. Adanya perwakilan dari masyarakat seperti tokoh masyarakat, tokoh agama, perangkat desa, dan ketua komunitas perempuan.

c. Adanya pemateri yang ahli dalam bidang tanggap bencana.

2) Faktor penghambat, yaitu kegiatan sosialisasi yang dilaksanakan berlangsung secara bersamaan dengan kegiatan posyandu sehingga mengganggu fokus peserta terhadap sosialisasi.

\section{Kesimpulan}

Berdasarkan hasil uraian pembahasan di atas dapat disimpulkan bahwa Desa Pijot merupakan desa yang menghadap ke laut dan berada sejauh $1 \mathrm{~km}$ dari laut, sehingga bencana alam seperti tsunami, sangat mungkin terjadi di desa tersebut. Adapun tujuan secara umum dari kegiatan ini yaitu untuk meningkatkan pengetahuan serta membangun kesadaran masyarakat yang ada di Desa Pijot dalam meningkatkan kemampuan kesiapsiagaan terhadap bencana alam dengan pemberian materi terkait tanggap bencana, sehingga tercipta Desa Pijot yang tangguh. Secara keseluruhan kegiatan dikatakan berhasil karena melebihi target yang ditetapkan walaupun terdapat beberapa hambatan dalam pelaksanaan kegiatan sosialisasi tersebut.

\section{Daftar Pustaka}

Diposaptono, D., dan Budiman. 2005. Tsunami. Bogor: Buku Ilmiah Populer.

Fadli, A., \& Masnun. (2020). The earthquake risk management model based on Sasak' local wisdom", Disaster Advances, 13(3), 54-61.

Noor, D. 2014. Pengantar Mitigasi Bencana Geologi. Yogyakarta: Deepublish.

Permana, C. E., Nasution, I., P., \& Gunawijaya, J. 2012. Kearifan Lokal tentang Mitigasi Bencana pada Masyarakat Baduy. HubsAsia, 10 (1).

RPJMDes. 2021. Rencana Pembangunan Jangka Menengah Desa Pijot. 
Santoso, D., M. Yamin., dan Muh. Mahrus. 2019. Penyuluhan tentang Mitigasi Bencana Tsunami berbasis Hutan Mangrove di Desa Ketapang Raya Kecamatan Keruak Lombok Timur. Jurnal Pengabdian Magister Pendidikan IPA, 1 (2).

Yayasan IDEP. 2007. Panduan Umum Penanggulangan Bencana Berbasis Masyarakat. Jakarta : Erlangga. 